\title{
Anatomia comparada dos órgãos do sistema vegetativo de três espécies de Encyclia (Orchidaceae: Epidendroideae)
}

\author{
Igor Soares dos Santos ${ }^{1, *}(\mathbb{D})$, Alexandre Antonio Alonso ${ }^{1}(\mathbb{D})$, Marcos José da Silva' \\ ' Universidade Federal de Goiás, Instituto de Ciências Biológicas, Departamento de Botânica, \\ Alameda Ingá, Quadra A, Campus Samambaia, 74001-970, Goiânia, Goiás, Brasil \\ *Autor para correspondência: igorsoares@discente.ufg.br
}

Recebido em 7.IX.2019

Aceito em 21.IX.2020

DOI 10.21826/2446-82312021v76e2021003

RESUMO - Encyclia Hook compreende 150 espécies distribuídas em vegetações florestadas e savânicas das Américas. Suas espécies apresentam anatomia dos órgãos vegetativos diversificada e útil taxonomicamente. Objetivou-se a descrição morfoanatômica dos órgãos do sistema vegetativo de Encyclia chapadensis L. C. Menezes, E. linearifolioides (Kraenzl.) Hoehne e E. osmantha (Barb. Rodr.) Schltr., visando levantar caracteres que as subsidiem em termos taxonômicos e que reflitam as condições ambientais. Algumas características dos órgãos estudados refletem adaptações à restrição hídrica (folhas suculentas e hipoestomáticas com hipoderme, raízes com velame expressivo e diferenciado em endo e epivelame, células armazenadoras de água e cutícula espessa), sustentação e suporte mecânico (fibras extravasculares e associadas aos feixes vasculares, espessamento em "fi" no córtex radicular), indicando que alguns caracteres anatômicos refletem as condições abióticas do ambiente impostas ao seu modo de vida. Os taxa podem ser diferenciados por caracteres foliares, caulinares e radiculares.

Palavras-chave: Laeliinae, micromorfologia, orquídeas, savanas

\begin{abstract}
Comparative anatomy of the organs of the vegetative system of three Encyclia Hook species (Orchidaceae: Epidendroideae). Encyclia comprises 150 species distributed in forest or savanic vegetations of the Americas. The anatomy of their vegetative organs is diversified and useful on taxonomic grounds. We aimed to describe the morphoanatomy of the vegetative system of Encyclia chapadensis L. C. Menezes, E. linearifolioides (Kraenzl.) Hoehne, and E. osmantha (Barb. Rodr.) Schltr., emphasizing these characters that are both, helpful to set them apart and reflect the ecological conditions of their habitats. Some observed characters reflect adaptations to water restriction (hypostomatic leaves with hypodermis, roots with thick velamen, differentiated in endo and epivelamen, pseudobulbs with water- storage cells and thick cuticle) and mechanical reinforcement for support tissues (vascular bundles with fibers, presence of extravascular fibers and thickening in "fi" in the radicular cortex), indicating that some anatomical features reflect some abiotic conditions of the environment. The studied taxa can be differentiated through leaf, stem and root characters.
\end{abstract}

Keywords: Laeliinae, micromorphology, orchids, savannas

\section{INTRODUÇÃO}

Encyclia Hook inclui cerca de 150 espécies distribuídas desde o sul da América do Norte ao sul da América do Sul, sendo no Brasil representado por 39 espécies (Bastos et al. 2015). Pertence à tribo Epidendreae Kunth, subtribo Laeliinae Benth. (Dressler 1993), e é facilmente diagnosticado pelos pseudobulbos ovoides com duas ou três folhas, inflorescências terminais, flores com labelo 3-lobado, caloso e não soldado à coluna (Bastos et al. 2015). Possui taxonomia complexa por incluir espécies morfologicamente semelhantes e de difícil delimitação, estudada por diversos autores (ex., Pupulin \& Bogarín 2012, Barbosa-Rodrigues 1882, 1891, Cogniaux 1898, Meneguzzo et al. 2012, Bastos et al. 2015) e em parte, relacionado aos gêneros Epidendrum L. e Prosthechea Knowles \& Westc. (van de Berg et al. 2009, Pires et al. 2003).
Estudos anatômicos em Orchidaceae Juss., direcionados à morfologia de órgãos vegetativos (ex., Solereder \& Meyer 1930, Baker 1972, Williams 1979, Stern 2014, Piazza et al. 2015), têm se mostrado úteis na delimitação e caracterização de subtribos (Stern et al. 2004, Stern \& Carlsward 2006, 2009, Carlsward et al. 2006, Figueroa et al. 2008, Carlsward \& Stern 2009a, b); gêneros (ex., Weltz 1897, Porembisk \& Barthlott 1988, Pires et al. 2003); seções (Piazza et al. 2015); espécies (Mohana Rao \& Khasim 1987, Holtzmeier et al. 1998, Oliveira \& Sajo 1999, Yukawa \& Stern 2002, Dettke et al. 2007), dentre outros, embora as variações anatômicas encontradas, muitas vezes estivessem relacionadas aos habitats nos quais as espécies se encontravam.

Se considerarmos a diversidade de Encyclia e sua complexidade, notamos uma lacuna no seu conhecimento anatômico, pois, cerca de 20 espécies (ca. 13,4\%), têm sua anatomia conhecida, e os poucos estudos existentes são 
generalistas e se direcionam à anatomia de órgãos isolados, tais como folhas (Möbius 1887, Baker 1972, Benzing \& Pridgeon 1983, Bonates 1993, Rosa-Manzano et al. 2014), raízes (Oudemans 1861, Benzing et al. 1983, Pridgeon et al. 1983, Pridgeon 1987, Parrilla Díaz \& Ackerman 1990, Moreira \& Isaias 2008, Staebner 2012, Fernándes-García et al. 2014, Ramírez et al. 2016, Joca et al. 2017, Einzmann et al. 2019, Joca et al. 2020) ou ambos (Benzing \& Ott 1981, Thorsch \& Stern 1997, Pires et al. 2003, Bonates 2007, Blanco 2017). Mesmo assim, diversos trabalhos evidenciaram que a anatomia foi útil para a delimitação do gênero em relação a outros de sua subtribo, como verificado por Pires et al. (2003) para Prosthechea e Epidendrum, o que revela a importância e a promissoriedade de estudos micromorfológicos em Encyclia.
Dessa maneira, com intuito de contribuir com a caracterização anatômica de Encyclia, levantar caracteres anatômicos úteis à taxonomia de suas espécies, apresentamos o estudo comparativo dos órgãos do sistema vegetativo de três espécies do gênero.

\section{MATERIAL E MÉTODOS}

As espécies estudadas foram coletadas no Parque Nacional da Chapada dos Veadeiros (PNCV), uma das Áreas de Preservação Permanente (APPs) mais importantes do Brasil, onde as mesmas foram fotografadas em distintas fitofisionomias do bioma Cerrado (Figs. 1A-C) e georreferenciadas. Posteriormente, os taxa foram identificados pelos autores do artigo por meio de literatura
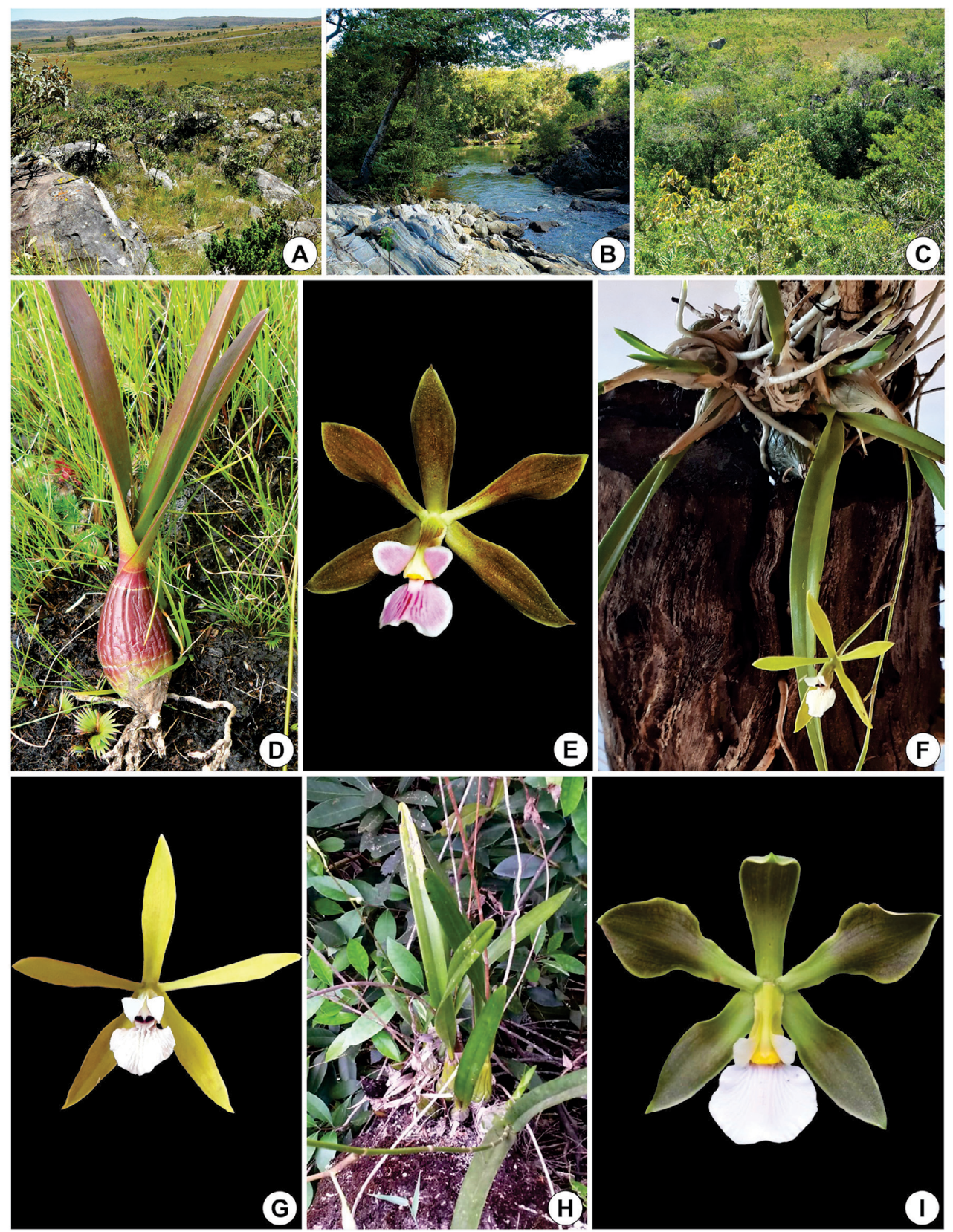

Figura 1. A-I. A-C. Habitats. A. Cerrado rupestre; B. Mata ciliar; C. Mata de galeria; D, F, H. Hábito; E, G, I. Flores. D-E. Encyclia chapadensis L.C. Menezes; F-G. E. linearifolioides (Kraenzl.) Hoehne; H-I. E. osmantha (Barb. Rodr.) Schltr. 
especializada (Meneguzzo et al. 2012, Bastos et al. 2015). Foram coletados cinco indivíduos adultos de Encyclia chapadensis L.C. Menezes (Figs. 1D, E), E. linearifolioides (Kraenzl.) Hoehne (Figs. 1F, G) e E. osmantha (Barb. Rodr.) Schltr. (Figs. 1H, I), dos quais, amostras de folhas, pseudobulbos, rizomas e raízes adventícias completamente desenvolvidas foram obtidas, fixadas em FAA 70\% (formaldeído, ácido acético glacial e álcool etílico 70\%, 1:1:18), durante 48 horas e preservadas em álcool etílico $70 \%$, seguindo as indicações de Johansen (1940). Das amostras coletadas foram retirados o terço mediano do limbo, pseudobulbos, rizomas e raízes, dos quais foram obtidas secções transversais, à mão livre, utilizando-se lâmina de barbear, enquanto que a dissociação da epiderme seguiu o método de Jeffrey (Johansen 1940). Tais secções foram clarificadas em solução de hipoclorito de sódio $20 \%$ (v/v) segundo as recomendações de Kraus \& Arduin (1997), e posteriormente, as mesmas foram lavadas em água destilada, submetidas à coloração com Azul de Astra e Safranina (9:1) (Bukatsch 1972), montadas em lâminas semipermanentes em glicerina aquosa $50 \%(\mathrm{v} / \mathrm{v})$ e vedadas com esmalte incolor.
Foram realizados testes histoquímicos em seções transversais de material fresco (acompanhados de grupos controle), para detecção de corpos silicosos, substâncias fenólicas e lipídios totais, com o uso de cristais de fenol, cloreto férrico e Sudan IV (Johansen 1940), respectivamente; de lignina com floroglucina em meio ácido, grãos de amido com Lugol (Sass 1951), celulose e lignina com cloreto de zinco iodado, e ácido acético glacial e ácido clorídrico a $10 \%$ para constatar a natureza química dos cristais conforme as recomendações de Chamberlain (1932), modificado apud Kraus \& Arduin (1997).

As lâminas confeccionadas foram fotografadas em sistema de captura de imagens, constituído por microcomputador com Software Motic 2.0 Image Plus, microscópio Leica DM500 ${ }^{\circledR}$ com câmera acoplada Leica ICC50 $\mathrm{HD}^{\circledR}$, com suas respectivas escalas. As descrições anatômicas seguiram as terminologias de Baker (1972), Pires et al. (2003) e de Stern \& Carlsward (2009). Informações sobre habitat das espécies, coletores, número de coleta, ambientes de ocorrência e herbário de deposição dos seus testemunhos são encontradas na Tabela. 1 .

Tabela. 1. Material testemunho analisado com seus respectivos coletores, números de coleta, herbário de deposição e locais onde as espécies foram coletadas.

\begin{tabular}{|c|c|c|}
\hline Espécie/ Forma de vida & Número de coletor/herbário & Bioma/Fitofisionomia \\
\hline $\begin{array}{l}\text { E. chapadensis } \\
\text { (rupícola) }\end{array}$ & I.S. Santos et al. 223, 241, 247, 427 (UFG) & Cerrado/Campo e cerrado rupestre \\
\hline $\begin{array}{c}\text { E. linearifolioides } \\
\text { (epífita) }\end{array}$ & I.S. Santos et al. 711 (UFG) & Cerrado/Mata de galeria e ciliar \\
\hline $\begin{array}{l}\text { E. osmantha } \\
\text { (epífita) }\end{array}$ & I.S. Santos et al. 73, 594 (UFG) & Cerrado/Mata de galeria e ciliar \\
\hline
\end{tabular}

\section{RESULTADOS E DISCUSSÃO}

\section{Folhas}

As espécies estudadas possuem folhas conduplicadas em secção transversal (Figs. 2A-C), sendo estas fortemente conduplicadas em $E$. linearifolioides e E. osmantha (Figs. 2B, C) em relação a E. chapadensis (Fig. 2A). O contorno da região da nervura central, voltando-se para a face abaxial, é arredondado e com uma pequena protuberância em $E$. chapadensis (Fig. 2D), plano em E. linearifolioides (Fig. 2E), e levemente anguloso em E. osmantha (Figs. 2F). O bordo é irregularmente obtuso em E. chapadensis (Fig. $2 \mathrm{G}$ ), arredondado em E. linearifolioides (Fig. $2 \mathrm{H}$ ) com ambas as faces com aspecto convexo e côncavo (Figs. $2 \mathrm{G}, \mathrm{H}$ ), e agudo, levemente fletido, com a face adaxial de aspecto convexo e abaxial plano em E. osmantha (Fig. 2I).

A epiderme é uniestratificada, com percurso reto ou discretamente ondulado, cutícula espessa e células comuns de tamanhos e formatos variados, sendo estas arredondadas, retangulares e transversalmente oblongas ou elípticas (Figs. 2J-L).

As folhas são hipoestomáticas, condição predominante em Laeliinae (Stern \& Carlsward 2009), com estômatos distribuídos no mesmo nível das demais células comuns da epiderme, com discretas câmaras subestomáticas e supraestomáticas com conspícuas cristas (Figs. 3A, B, D), que atuam no controle da saída de vapor de água e na entrada de dióxido de carbono, contribuindo assim para baixas taxas de transpiração, mesmo quando os estômatos estão totalmente abertos, como observado por Rosso (1966), Rasmussen (1987) e Oliveira \& Sajo (1999) para outras espécies epífitas de Orchidaceae. Folhas hipoestomáticas também são reportadas para outros grupos de Orchidaceae como em representantes da tribo Cranichideae Endl. (Andreota et al. 2015) e do gênero Habenaria Willd. (Dangat \& Gurav 2016), revelando que, apesar de predominante em Laeliinae e em muitos outros grupos de Orchidaceae, esta característica evoluiu de maneira independente em diversos grupos de plantas vasculares.

Em vista frontal as células epidérmicas apresentamse retangulares, pentagonais, hexagonais e arredondadas com paredes periclinais e anticlinais retas ou ligeiramente curvas em E. chapadensis (Fig. 3E), E. osmantha (Fig. 3F), e E. linearifolioides (Fig. 3G), diferindo apenas pelo tamanho e disposição das células subsidiárias (Figs. 3EG). Nestas figuras observam-se estômatos tetracíticos em E. chapadensis e E. linearifolioides, (Figs. 3E, F) e 

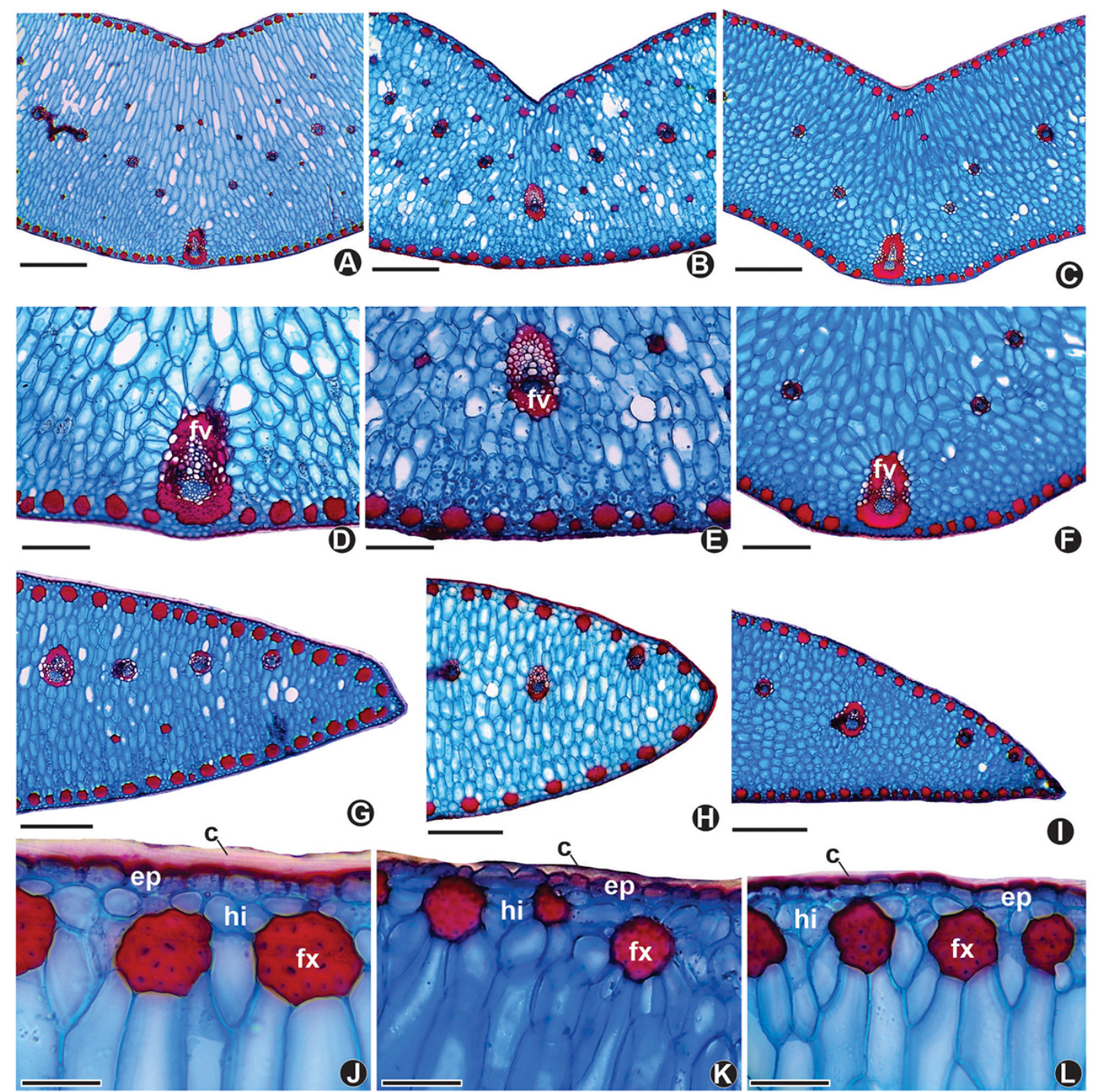

Figura 2. A-L. Folhas em secção transversal. A, D, G, J. Encyclia chapadensis L.C. Menezes; B, E, H, K. E. linearifolioides (Kraenzl.) Hoehne; C, F, I, L. E. osmantha (Barb. Rodr.) Schltr.; A-C. Região da nervura central; D-F. Face abaxial da lâmina foliar; G-I. Bordo; J-L. Face adaxial da lâmina foliar. $\mathrm{c}=$ cutícula; $\mathrm{ep}=$ epiderme; $\mathrm{fv}=$ feixes vasculares; $\mathrm{fx}=$ fibras extravasculares; hi $=$ hipoderme. Barras: Figuras A-C, G-I = 500 $\mu \mathrm{m}$; Figs. D-F $=200 \mu \mathrm{m}$; Figuras J-L $=50 \mu \mathrm{m}$.

anomocíticos em E. osmantha (Fig. 3G), conforme também foi observado para outras espécies de Encyclia por Pires et al. (2003) e Stern \& Carlsward (2009), e gêneros de Laeliinae, tais como, Cattleya Lindl., por Zanenga-Godoy \& Costa (2003), Ribeiro et al. (2020) e Orleanesia Barb. Rodr. (Krahl \& Krahl 2017). Tais estômatos possuem paredes periclinais das células guardas mais espessadas que as anticlinais, conforme já reportado para outras espécies de Encyclia por Pires et al. (2003), Baker (1972) e Stern \& Carlsward (2009) para outros taxa de Laeliinae. Todas as espécies estudadas apresentaram estômatos majoritariamente tetracíticos. Entretanto, E. osmantha apresentou estômatos tetracíticos e anomocíticos.

A hipoderme é uniestratificada em ambas as faces, composta por células justapostas com formatos similares aos da epiderme, porém, maiores (Figs. 2J-L). Conforme Haberlandt (1914), Madison (1977), Scatena \& Nunes
(1996), Oliveira \& Sajo (1999), a presença de hipoderme foliar é comum em espécies de diferentes famílias botânicas (ex., Bromeliaceae Juss., Gesneriaceae Rich. \& Juss., Orchidaceae Juss., entre outras), sendo considerada uma estrutura relacionada ao armazenamento de água ou economia de calor, sobretudo, em espécies epífitas, mas conforme Kraus (1949) e Costa (1989), ela também exerce função de sustentação. De acordo com Withner et al. (1974), Leite \& Oliveira (1987), Oliveira \& Sajo (1999), a cutícula mais ou menos espessada, células da epiderme maiores na face adaxial da folha e presença de hipoderme relacionam-se às condições ambientais e são, portanto, de pouco valor taxonômico.

O mesofilo das espécies estudadas é homogêneo, possui diminutos espaços intercelulares, com 23-25 camadas de células em E. chapadensis (Fig. 2A), 20-22 em E. linearifolioides (Fig. 2B) e 19-20 em E. osmantha (Fig. 2C), 

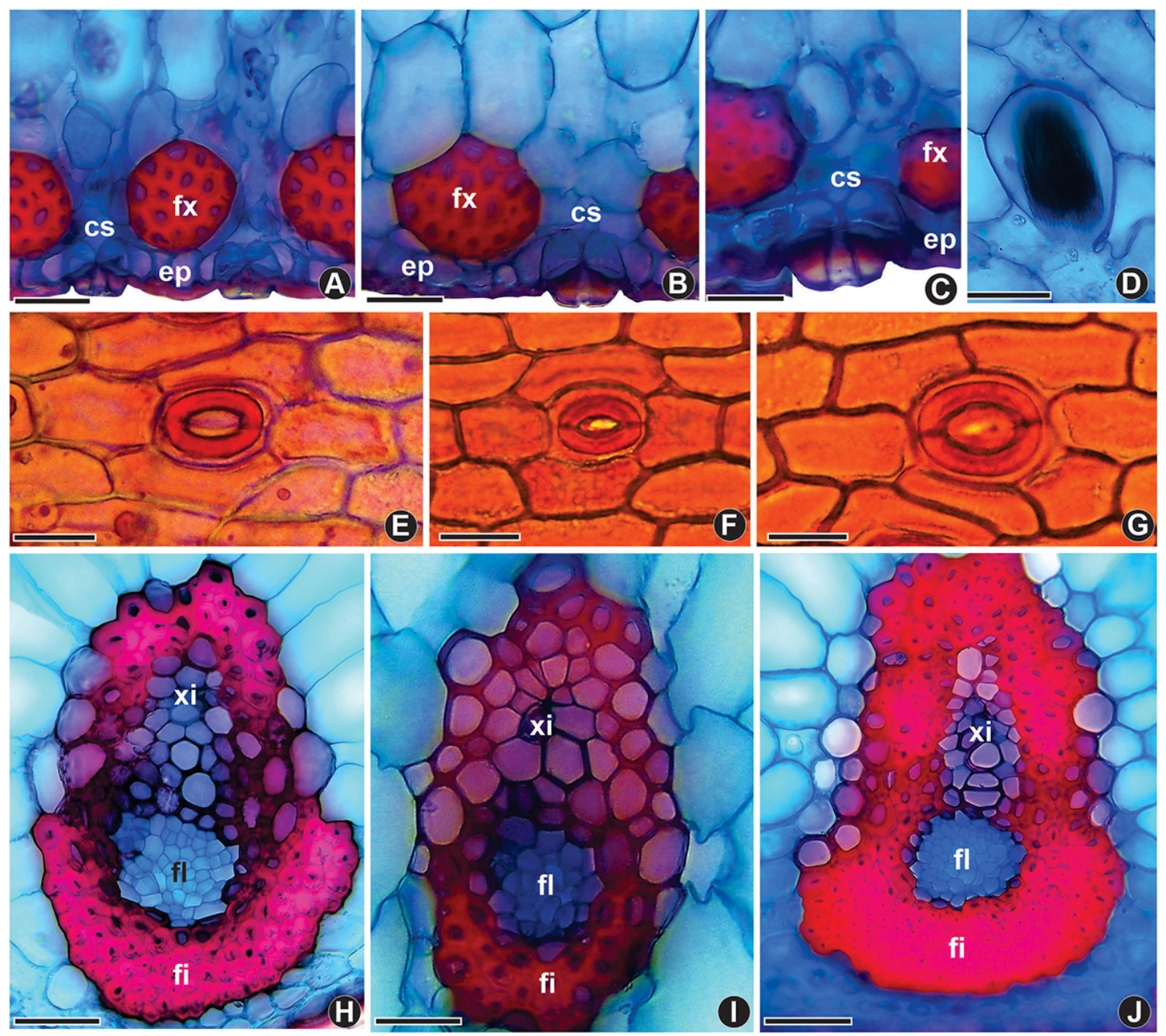

Figura 3. A-J. A-C, H-J. Folhas em secção transversal. E-G. Epiderme em vista frontal. A, E, H. Encyclia chapadensis L.C. Menezes; B, D, F, I. E. linearifolioides (Kraenzl.) Hoehne; C, G, J. E. osmantha (Barb. Rodr.) Schltr.; A-C. Vista da face abaxial evidenciando os estômatos e as fibras extravasculares; D. Idioblasto com ráfides; E-G. Epiderme em vista frontal, evidenciando os estômatos; H-I. Feixes vasculares da nervura central. $\mathrm{cs}=$ câmara subestomática; $\mathrm{ep}=$ epiderme; $\mathrm{fi}=$ fibras; $\mathrm{fl}=$ floema; $\mathrm{fx}=$ fibras extravasculares; $\mathrm{xi}=$ xilema. Barras: Figuras A-J $=50 \mu \mathrm{m}$.

sendo as células arredondadas, elípticas, pentagonais ou hexagonais com dimensões variadas. As figuras mostram diferenças entre os tamanhos das células voltadas para a face adaxial em relação à abaxial (Figs. 2A-C). No mesofilo ocorrem feixes de fibras extravasculares lignificadas, dispostas em fileiras, em posição subepidérmica em ambas as faces foliares de todas as espécies (Figs. 2J-L, 3A-C), sendo ainda encontrados ladeando os feixes vasculares na porção mediana do mesofilo, dispostos em duas fileiras em E. chapadensis e E. linearifolioides (Figs. 2A, B), chegando até o bordo apenas de E. chapadensis (Fig. 2G), enquanto que $E$. osmantha apresenta fibras extravasculares apenas na região subepidérmica de ambas as faces (Figs. 2C, I).

Para diversos autores (Krauss 1949, Withner et al. 1974, Brighigma et al. 1984, Oliveira \& Sajo 1999 e Silva et al. 2006, Krahl et al. 2013, Krahl \& Krahl 2017), tais estruturas conferem rigidez e resistência mecânica às folhas das orquídeas, oferecendo-lhes sustentação por ocasião de ventanias, sendo comumente encontrados em espécies epífitas ou que crescem em ambientes com certa restrição hídrica, como as estudadas. De acordo com Eames \& MacDaniels (1925), Zanenga-Godoy \& Costa (2003), tais estruturas atuam filtrando a intensidade luminosa, pois funcionam como uma barreira contra a incidência de raios luminosos, não permitindo que estes atinjam os tecidos mais internos, o que poderia levar a um superaquecimento. Este tipo de disposição de feixes de fibras extravasculares parece ser comum em Orchidaceae e em Laeliinae como visto nos taxa estudados por Baker (1972), Pires et al. (2003), Stern \& Carlsward (2009) e Ribeiro et al. (2020). As fibras extravasculares encontradas em Orleanesia yauaperyensis Barb. Rodr. por Krahl \& Krahl (2017), mostraram-se semelhantes nas espécies estudadas quanto à sua disposição.

As espécies estudadas apresentam feixes vasculares dispostos paralelamente em relação ao eixo longitudinal do limbo foliar, caracterizando o padrão de venação paralelódromo. Estes são colaterais, ocorrem 
predominantemente na porção mediana do mesofilo, sendo os de maior calibre, correspondentes à nervura central, voltados para a face abaxial, distribuindo-se em posição subepidérmica em $E$. chapadensis (Fig. 2D) e $E$. osmantha (Fig. 2F) e na porção mediana do limbo em $E$. linearifolioides (Fig. 2E). Fibras perivasculares ocorrem junto ao floema e ao xilema em E. chapadensis (Fig. 3H) e E. linearifolioides (Fig. 3I), ou circundam conspicuamente os feixes vasculares em E. osmantha (Fig. 3J). Estes feixes, em todas as espécies, são ainda envoltos por endoderme, cujas células se distinguem das demais do mesofilo pelas paredes delgadas e disposição geralmente radial, como observado por Oliveira \& Sajo (1999), para outras espécies de Orchidaceae, incluindo, Encyclia calamaria (Lindl.) Pabst, e por Pires et al. (2003) para outras sete espécies de Encyclia, incluindo E. linearifolioides, espécie aqui estudada. Ráfides foram encontradas no mesofilo, próximo aos feixes vasculares em E. linearifolioides (Fig. 3D).

\section{Pseudobulbos}

São ovoides (Figs. 1D, F, H) com contorno circular em seção transversal (Figs. 4A-C) em todas as espécies. A
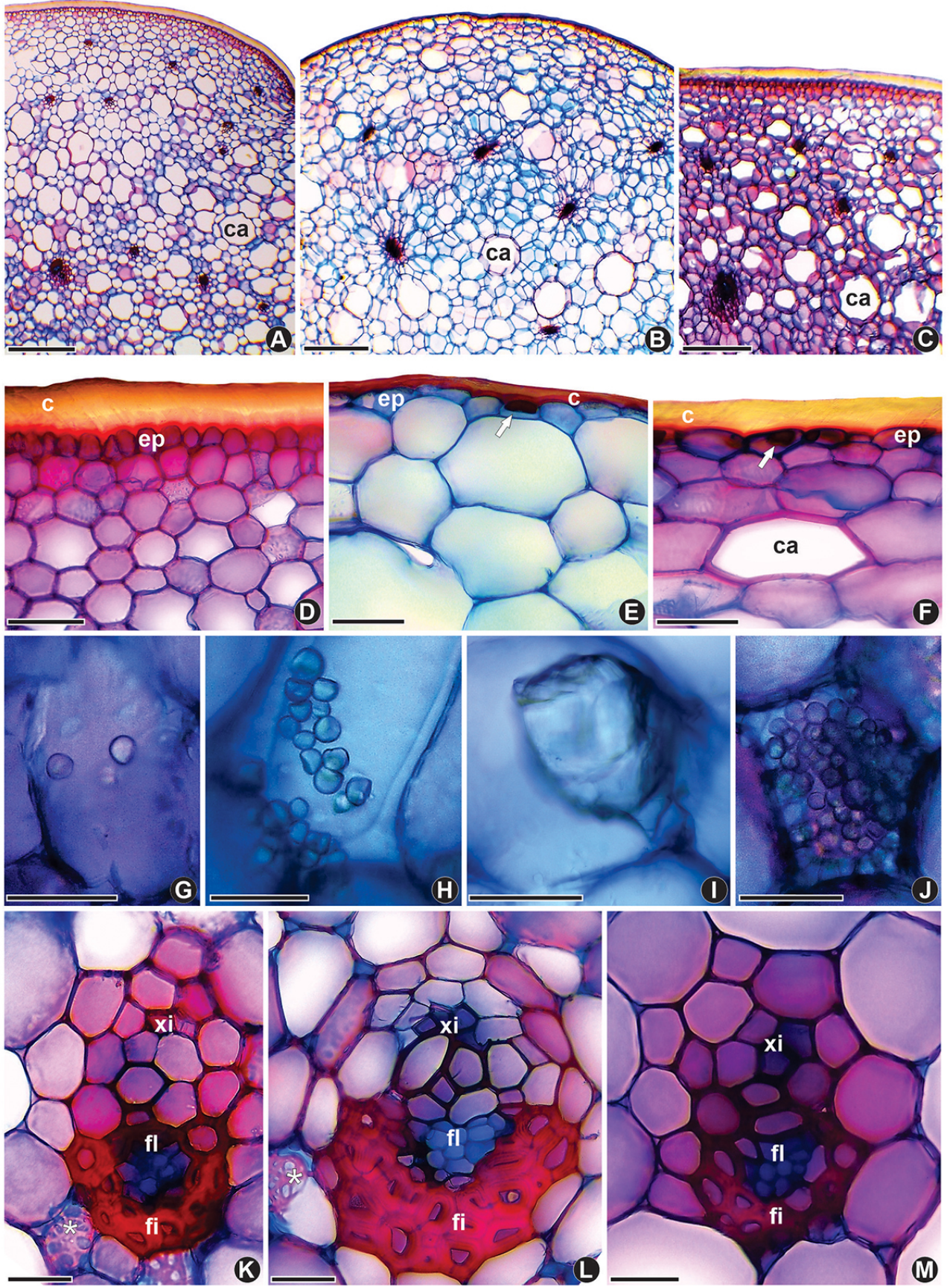

Figura 4. A-M. Pseudobulbos em secção transversal. A, D, G, K. Encyclia chapadensis L.C. Menezes; B, E, H, I, L. E. linearifolioides (Kraenzl.) Hoehne; C, F, J, M. E. osmantha (Barb. Rodr.) Schltr.; A-C. Aspecto geral; D-F. Epiderme; G, H e J. Grãos de amido; I. Cristal irregular; K-M. Feixes vasculares. $\mathrm{c}=$ cutícula; $\mathrm{ca}=$ célula armazenadora de água; $\mathrm{ep}=$ epiderme; $\mathrm{fl}=$ floema; $\mathrm{fi}=$ fibras; $\mathrm{xi}=\mathrm{xilema} ;$ * $=$ Idioblasto traqueoidal de espessamento parietal reticulado; corpos silicosos $=$ setas. Barras: Figuras A-C $=500 \mu \mathrm{m}$; Figuras D-F $=200 \mu \mathrm{m}$; Figuras G-M $=50 \mu \mathrm{m}$. 
análise anatômica revelou que a epiderme está recoberta por cutícula mais espessa, sobretudo, em E. chapadensis (Fig. 4D) e E. osmantha (Fig. 4F), em comparação a $E$. linearifolioides (Fig. E). A epiderme é uniestratificada, e em secção transversal, apresenta células geralmente ovoides e sem corpos silicosos em E. chapadensis (Fig. 4D), ou arredondadas, elípticas ou oblongas, algumas das quais com corpos silicosos em E. linearifolioides (Fig. 4E) e $E$. osmantha (Fig. 4F). A cutícula espessa dos pseudobulbos reduz a perda de água deste órgão para o meio externo, e reflete a capacidade das espécies em explorar ambientes com menor disponibilidade de água (Vieira et al. 2000, Oliveira \& Sajo 2001). Em secção transversal, as células do parênquima apresentam tamanhos e formatos variados (arredondadas, hexagonais, pentagonais), sendo as maiores armazenadoras de água, com paredes celulares espessas, e as demais contendo grãos de amido (Figs. 4D-J), sendo comumente encontrados em órgãos de reserva (Takane et al. 2010). Cristais de formato irregular foram encontrados no córtex de E. linearifolioides (Fig. 4I). Neste órgão há inúmeros feixes vasculares dispersos aleatoriamente, sendo os mais calibrosos voltados para a região central e os de menor calibre, para sua periferia. Tais feixes são do tipo colateral e possuem fibras perivasculares junto ao floema (Figs. 4K-M). Idioblastos traqueoidais de espessamento parietal do tipo reticulado foram encontrados no parênquima de preenchimento e adjacentes aos feixes vasculares (Figs. 4K, L).

\section{Rizomas}

Apresentam contorno circular em secção transversal (Figs. 5A-C). A epiderme, similarmente à do pseudobulbo é uniestratificada, revestida por uma cutícula espessa e ondulada em E. chapadensis (Fig. 5D), lisa em $E$. linearifolioides (Fig. 5E), e fortemente irregular em E. osmantha (Fig. 5F). Suas células comuns possuem dimensões e formatos variados nas espécies estudadas, porém em E. chapadensis (Fig. 5D) e em E. osmantha (Fig. 5F), estas possuem formatos arredondados ou ovoides e paredes espessadas, quando comparadas a E. linearifolioides (Fig. 5E), na qual são tabulares ou transversalmente oblongas e elípticas, com corpos silicosos, enquanto que estes últimos não foram observados em $E$. chapadensis (Fig. 5D).

O córtex, nas espécies estudadas, compreende 20-35 camadas de células parenquimáticas de preenchimento, com formatos e dimensões variadas e paredes geralmente espessadas, sendo aquelas voltadas para a periferia ou centro deste órgão, menores que as demais. E. chapadensis apresenta 20-26 camadas de células (Fig. 5A), enquanto que E. linearifolioides têm 20-35 (Fig. 5B), e E. osmantha 22-25 camadas (Fig. 5C). Nessa região, há células de maior tamanho, globosas, armazenadoras de água, cujas paredes celulares são espessadas (Figs. 5D-F), ou de grãos de amido (Figs. 5G, I, J), similarmente às do pseudobulbo. Células armazenadoras de água foram reportadas por Haberlandt
(1914), Pridgeon (1986), Stern \& Morris (1992), Stern et al. (1993a, b), Oliveira \& Sajo (2001) e Saoncella et al. (2017) para outras espécies epífitas de Orchidaceae, e para plantas de uma maneira geral por Esau (1974), enquanto que as células armazenadoras de grãos de amido, conforme Holttum (1955) são usadas como reserva energética. Foram encontrados cristais poliédricos nas células do córtex de E. chapadensis (Fig. 5H).

$\mathrm{O}$ estelo compreende diversos feixes vasculares colaterais (Figs. 5A-C) em um padrão atactostélico, estruturalmente similares àqueles encontrados nos pseudobulbos. Estes feixes possuem fibras perivasculares junto ao floema, ou circundando-os completamente, além de endoderme composta por células parenquimáticas de paredes delgadas (Figs. 5K-M). Adicionalmente, idioblastos traqueoidais de espessamento parietal do tipo reticulado foram encontrados em todas as espécies, difusos pelo parênquima de preenchimento e próximos aos feixes vasculares (Figs. 5G, H, K-M).

\section{Raízes}

Os taxa estudados possuem raízes com contorno cilíndrico em secção transversal (Figs. 6A-C), epiderme pluriestratificada (velame), sendo composta de oito ou nove camadas em E. chapadensis (Fig. 6D), sete ou oito em E. linearifolioides (Fig. 6E) e 10-13 em E. osmantha (Fig. 6F). A camada mais externa da epiderme corresponde ao epivelame, cujas células são tão longas quanto largas, de tamanhos variados, paredes anticlinais e periclinal externa delgadas, formato predominantemente pentagonal, enquanto as demais correspondem ao endovelame, cujas células são predominantemente hexagonais, mais alongadas no sentido anticlinal. Quanto às estriações da parede celular, tanto o epivelame quanto o endovelame apresentam espessamento do tipo reticulado, conforme foi observado em alguns representantes de Pleurothallidinae Lindl. (Kedrovski 2014). Acredita-se que esses espessamentos atuam na estabilidade das células mortas e cheias de ar que constituem o velame (Porembski \& Barthlott 1988).

Velame diferenciado em epi e endovelame é comum em vários gêneros de Laeliinae, como foi verificado por Pires et al. (2003) e Carlsward \& Stern (2009a) em espécies de Cattleya, Epidendrum, Laelia Lindl., Prosthechea e Scaphyglottis Poepp. \& Endl., sendo o velame do tipo "Epidendrum", característico desta subtribo, conforme Porembski \& Barthlott (1988). Segundo Engard (1944) e Dycus \& Knudson (1957) o velame em Orchidaceae associa-se predominantemente ao hábito epifítico, porém pode também ocorrer em orquídeas rupícolas e terrícolas (Porembski \& Barthlott 1988, Stern et al. 1993c, Kurzweil et al. 1995). Tal estrutura confere proteção contra os danos causados por raios ultravioleta (UV-B), tais como: peroxidação lipídica da membrana plasmática, lesões no DNA e degradação do maquinário fotossintético (Jansen et al. 1998, Sinha \& Häder 2002, Bray \& West 2005, 

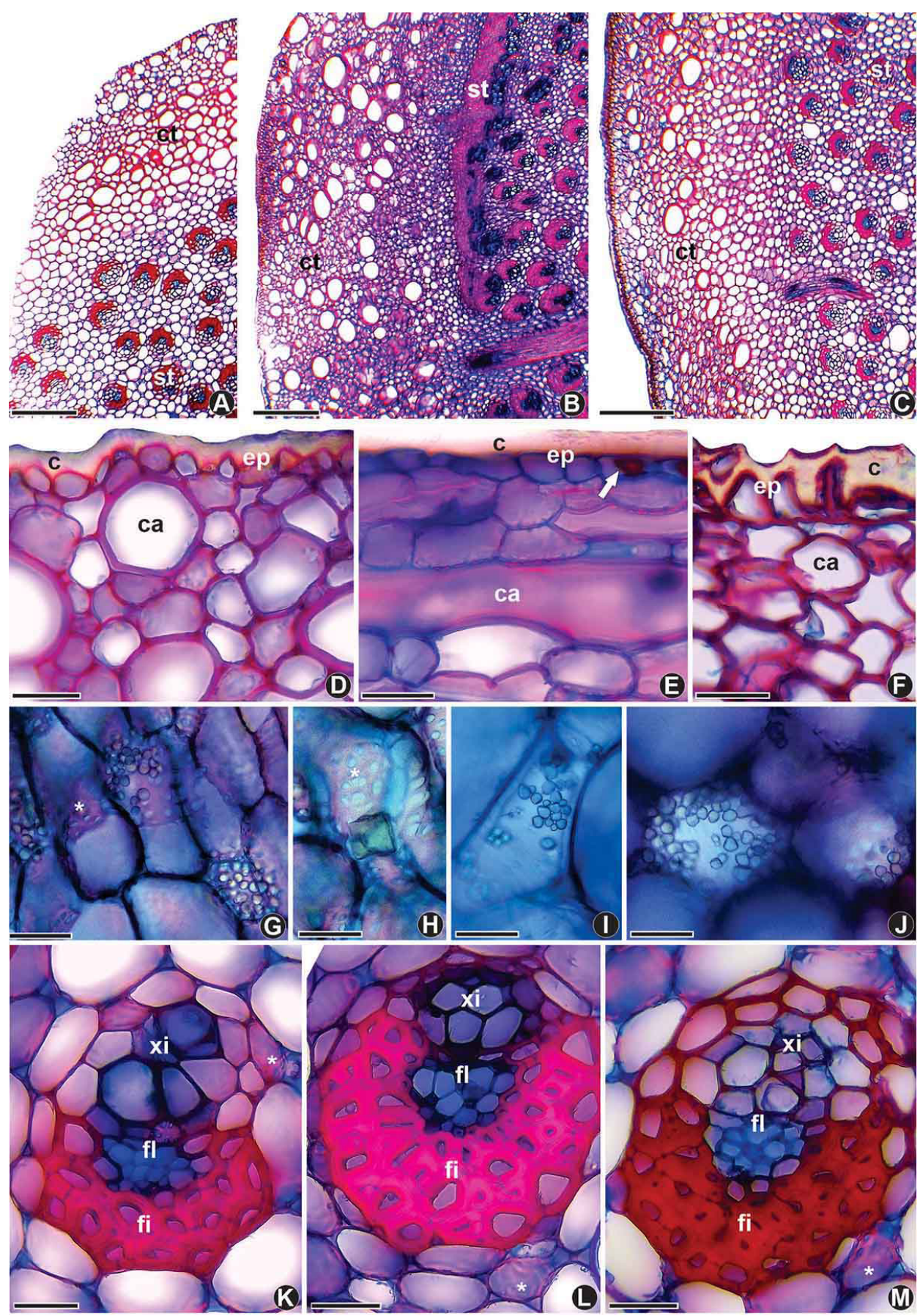

Figura 5. A-M. Rizomas em secção transversal. A, D, G, H, K. Encyclia chapadensis L.C. Menezes; B, E, I, L. E. linearifolioides (Kraenzl.) Hoehne; C, F, J, M. E. osmantha (Barb. Rodr.) Schltr.; A-C. Aspecto geral; D-E. Epiderme e células armazenadoras de água difusas pelo parênquima de preenchimento; G, I, J. Grãos de amido; H. Cristal romboide; K-M. Feixes vasculares. c $=$ cutícula; ca $=$ célula armazenadora de água; ct $=$ córtex; $\mathrm{ep}=$ epiderme; $\mathrm{fl}=$ floema $\mathrm{fi}=$ fibras; $\mathrm{st}=$ estelo; $\mathrm{xi}=\mathrm{xilema}$; $\operatorname{corpos}$ silicosos $=$ setas. Barras: Figuras A-C $=500 \mu \mathrm{m} ; \mathrm{Figuras} \mathrm{D}-\mathrm{F}=200$ $\mu \mathrm{m}$; Figuras $\mathrm{G}-\mathrm{M}=50 \mu \mathrm{m}$.

Chomicki et al. 2014b). As raízes, em algumas orquídeas, desempenham função fotossintética, muitas vezes, chegando a substituir a função das folhas; o velame garante a proteção dos tecidos internos da raiz, evitando o aquecimento do órgão; atua na absorção de maneira passiva e na retenção de água, além de prover suporte mecânico às raízes, evitando o colapso das células durante a desidratação, uma vez que possuem paredes pectocelulósicas com impregnação de lignina e suberina (Benzing et al. 1982, 1983, Pridgeon 1987, Chomicki et al. 2014a, b). Acredita-se que esta estrutura dinâmica e multifuncional tenha contribuído com a expansão da família Orchidaceae pelas florestas tropicais durante o Cenozoico (Chomicki et al. 2014a).

$O$ córtex destas espécies consiste de 8-9 camadas em $E$. chapadensis (Fig. 6D), 7-8 em E. linearifolioides (Fig. 6E) e 10-14 em E. osmantha (Fig. 6F). A exoderme apresenta 


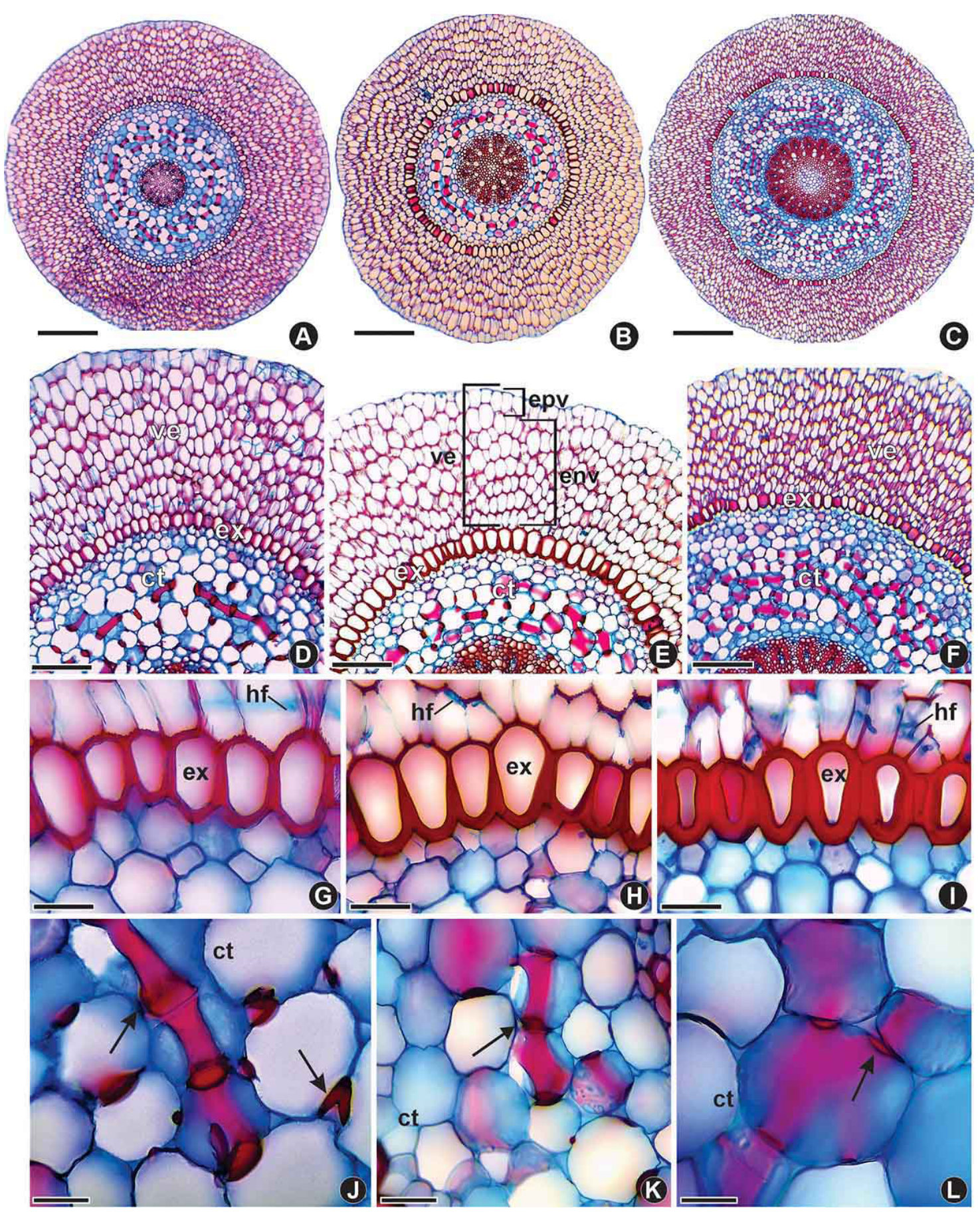

Figura 6. A-L. Raízes em secção transversal. A, D, G, J. Encyclia chapadensis L.C. Menezes; B, E, H, K. E. linearifolioides (Kraenzl.) Hoehne; C, F, I, L. E. osmantha (Barb. Rodr.) Schltr.; A-C. Aspecto geral; D-F. Velame, exoderme e córtex; G-I. Detalhe da exoderme; J-L. Detalhe do espessamento em " $\mathrm{fi}$ " no parênquima cortical $=$ setas; $\mathrm{ct}=\mathrm{có}$ rtex; $\mathrm{epv}=$ epivelame; $\mathrm{env}=$ endovelame; $\mathrm{ex}=\mathrm{exoderme}$; $\mathrm{hf}=\mathrm{hifas}$; ve $=\mathrm{velame}$. Barras: Figuras A-C $=500 \mu \mathrm{m}$; Figuras D-F $=200 \mu \mathrm{m}$; Figuras $\mathrm{G}-\mathrm{L}=50 \mu \mathrm{m}$.

espessamento em "O" em E. chapadensis (Fig. 6G) e em E. osmantha (Fig. 6I), e em "U" em E. linearifolioides (Fig. 6H). O parênquima possui células com paredes ligeiramente espessadas intercaladas com células de paredes delgadas, com dimensões variadas, formatos arredondados, pentagonais e hexagonais, sendo as da região mediana maiores que aquelas adjacentes à exoderme e endoderme (Figs. 6D-F). Observa-se ainda, no córtex das espécies estudadas, espessamentos de parede lignificado em "fi" do tipo III, conforme Van Tieghem (1988) e Idris \& Collings (2015), com a ocorrência de bandas largas, ramificadas ou não, dispostas concentricamente de maneira tangencial ou radial em relação às demais células (Figs. 6J-L).

Córtex com espessamento de parede do tipo "fi" foram reportados por Joca et al. $(2017,2020)$ para Encyclia jenischiana (Rchb. f.) Porto \& Brade, e Pires 
et al. (2003) para outras espécies de Encyclia (9 spp.), Prosthechea (7 spp.), Epidendrum (1 sp.) e Oncidium Sw. (1 sp.); por Carlsward \& Stern (2009) e Stern \& Judd (2001) para diversos taxa de Laeliinae e Catasetinae Lindl., respectivamente. Conforme Van Tieghem (1871), Haas et al. (1976), Mackenzie (1979), Peterson et al. (1981), Weerdenburg \& Peterson (1983), Christodoulakis \& Psaras (1987), Melville et al. (1987), Passioura (1988), Pratikakis et al. (1998), Pan et al. (2006) e Yim et al. (2013), tais estruturas evoluíram independentemente entre diversos grupos de Angiospermas e Gimnospermas, e parecem ser comuns em Encyclia. Tais estruturas, de acordo com os autores supracitados, desempenham funções de sustentação mecânica, dando suporte dos tecidos em processo de expansão radial e de crescimento longitudinal, servindo também como barreira física contra a invasão de fungos patogênicos em camadas mais profundas do córtex ou no cilindro central, seleção e fluxo de íons por via apoplástica, e aporte mecânico às células do parênquima cortical, evitando o colapso celular durante o stress hídrico ou durante a expansão celular.

$\mathrm{O}$ cilindro central das espécies estudadas varia em calibre (Figs. 6A-C, 7A-C), compreendendo um periciclo uniestratificado composto por células arredondadas esclerificadas, exceto em direção aos pólos de protoxilema, onde se encontram as células de passagem de paredes delgadas em número de 1-3 (Figs. 7D-F). As raízes destas espécies são poliarcas, com 9 pólos em E. chapadensis (Fig. 7A), $10 \mathrm{em}$ E. linearifolioides (Fig. 7B) e 18-19 em E. osmantha (Fig. 7C). A medula, em todas as espécies, compreende células arredondadas, quadrangulares, triangulares e pentagonais, sendo todas esclerificadas em E. chapadensis (Fig. 7G) e em E. linearifolioides (Fig. 7H), enquanto que em $E$. osmantha, esta é composta por células parenquimáticas centrais e esclerificadas periféricas (Fig. 7I).

Raízes com medula semelhante à das espécies estudadas são comuns em Laeliinae, como reportado por Blanco (2017) para Encyclia patens Hook., em Saoncella et al. (2017) para Cattleya violacea (Kunth) Rolfe, e em Silva \& Milaneze-Gutierre (2004) para C. walkeriana Gardner, bem como por Ribeiro et al. (2020) para C. caulescens (Lindl.) van den Berg e C. endsfeldzii (Pabst) van den Berg. Entretanto, essa característica pode ser observada em representantes de Oncidiinae Benth. conforme foi observado em Gomesa flexuosa (Lodd.) M.W. Chase \& N.H. Williams, e em um híbrido de Oncidium por Costa et al. (2012).

Hifas fúngicas foram observadas principalmente no velame (Figs. 6G-I), sendo menos frequentes no parênquima cortical e em algumas células da exoderme, chegando a formar pelotons, estruturas fúngicas adensadas e parcialmente digeridas por ação enzimática e por autólise (Peterson et al. 1998, Pereira et al. 2003). A presença de pelotons na porção mais externa do córtex é uma importante fonte de inóculo para a manutenção das hifas no velame, assim como para outras plantas circunvizinhas e sementes que se encontram próximas às raízes (Pereira $e t$ al. 2005). Os fungos desempenham um papel importante para a germinação das sementes diminutas e desprovidas de endosperma das orquídeas por meio de associações simbiontes com estas, onde o fungo facilita a absorção de água do substrato e fornece nutrientes como fósforo e nitrogênio para a planta em troca de açúcares (Cameron et al. 2007, Dearnaley 2007).

As espécies estudadas se diferenciam por caracteres foliares (ex., números de camadas do mesofilo, contorno e orientação do bordo e da região correspondente à nervura central, voltada para ambas as faces, presença de feixes de fibras extravasculares na região mediana do limbo, número de fileiras de fibras extravasculares, posição do feixe vascular de maior calibre correspondente à nervura central na região mediana do limbo, tipos de estômatos e distribuição das fibras associada aos feixes vasculares); dos pseudobulbos (formato das células epidérmicas, presença ou ausência de corpos silicosos, espessura da cutícula e tipo de cristais); dos rizomas (aspecto de ornamentação da cutícula, formato das células epidérmicas, número de camadas do parênquima cortical, presença ou ausência de corpos silicosos, tipos de cristais), e das raízes (número de camadas do velame e do parênquima cortical, tipo de espessamento das células da exoderme, número de pólos de protoxilema e pela composição das células da medula, onde estas são parenquimáticas ou esclerificadas). Os caracteres diferenciais supracitados estão sumarizados nos Quadros 1 e 2 . Por outro lado, são comuns às mesmas e às Orchidaceae epífitas a presença de folhas hipoestomáticas com mais de um tipo de estômato e com hipoderme, pseudobulbos com cutícula espessada, mesofilo homogêneo com fibras extravasculares em posição subepidérmica, fibras associadas aos feixes vasculares; pseudobulbo e rizomas com células armazenadoras de água e de amido, raízes com velame diferenciado em epi e endovelame, exoderme com diferentes tipos de espessamento e numerosos pólos de protoxilema.

Os testes histoquímicos revelaram a presença de lignina nas fibras associadas aos feixes vasculares e nos elementos de vaso do xilema, assim como nas células que constituem o velame, o córtex (exoderme, espessamentos em "fi" presentes no parênquima cortical e endoderme) o periciclo, e o cilindro central dos órgãos analisados. A reação positiva com Lugol confirmou a presença de grãos de amido nos pseudobulbos e rizomas, e a natureza química dos cristais de oxalato de cálcio pela solubilidade destes em meio ácido, assim como a natureza lipídica da cutícula pela reação com Sudan IV. Substâncias fenólicas não foram detectadas nos órgãos analisados.

Algumas características dos órgãos estudados refletem adaptações das espécies à restrição hídrica e ao epifitismo em seus ambientes de ocorrência (folhas suculentas, hipoestomáticas, presença de hipoderme, raízes com expressivo velame, pseudobulbos com células de armazenamento de água e cutícula espessa), sustentação e suporte mecânico (fibras extravasculares ou associadas aos feixes vasculares, espessamento em "fi" no 
parênquima cortical das raízes e idioblastos traqueoidais de espessamento parietal do tipo reticulado). Fato esse evidenciado em E. chapadensis, espécie encontrada como rupícola em campos e cerrados rupestres, que apresentou a cutícula e a parede anticlinal externa das células epidérmicas aparentemente mais espessadas nos órgãos analisados, sobretudo, nas folhas e pseudobulbos, órgãos que ficam mais expostos a uma grande incidência de raios solares, enquanto que suas demais congêneres, que crescem como epífitas, geralmente, em locais sombreados, no interior de matas ciliares e de galeria, apresentaram cutícula e parede anticlinal externa das células epidérmicas menos
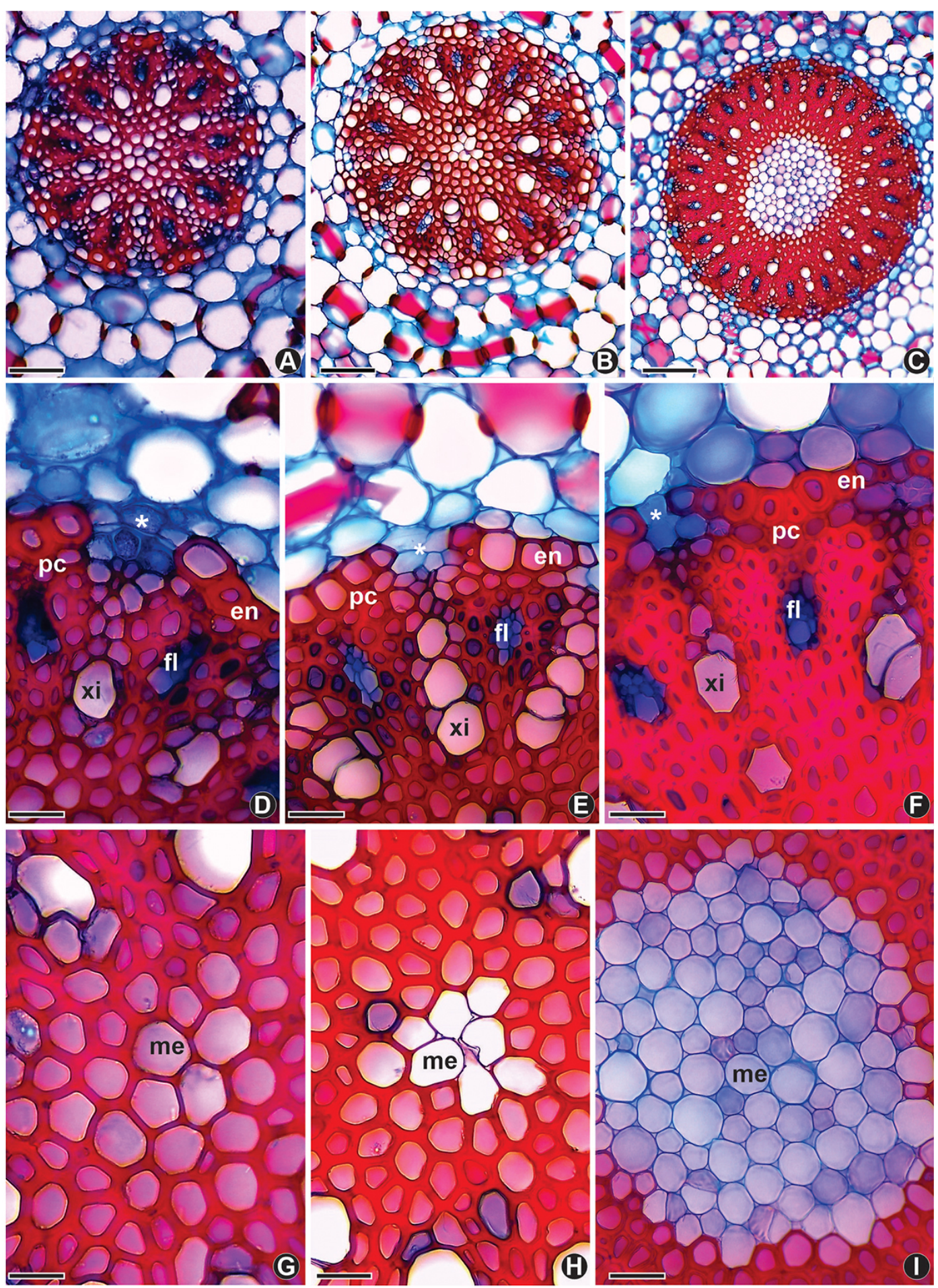

Figura 7. A-I. Raízes em secção transversal. A, D, G. Encyclia chapadensis L.C. Menezes; B, E, H. E. linearifolioides (Kraenzl.) Hoehne; C, F, I. E. osmantha (Barb. Rodr.) Schltr.; A-C. Cilindro central; D-F. Detalhe do cilindro central; G, H. Medula com células esclerificadas; I. Medula com células parenquimáticas centrais e esclerificadas periféricas; $\mathrm{en}=$ endoderme; $\mathrm{pc}=$ periciclo; $\mathrm{fl}=$ floema; me $=$ medula; $\mathrm{xi}=\mathrm{xilema;} *=\mathrm{células}$ de passagem. Barras: Figuras A-C $=200 \mu \mathrm{m}$; Figuras D-I $=50 \mu \mathrm{m}$. 
Quadro 1. Caracteres analisados das folhas, dos pseudobulbos, dos rizomas e das raízes.

\begin{tabular}{|c|c|}
\hline CARACTERES & DESCRIÇÃO \\
\hline 1 & Folhas fortemente conduplicadas, face adaxial em forma de "V" \\
\hline 2 & Folhas levemente conduplicadas, côncavas, face adaxial em forma de "U" \\
\hline 3 & Contorno da região da nervura central, voltando-se para a face abaxial \\
\hline 4 & Número de camadas do mesofilo \\
\hline 5 & Posição do feixe vascular correspondente a nervura central \\
\hline 6 & Feixes vasculares das folhas com fibras junto ao floema e ao xilema \\
\hline 7 & Feixes vasculares das folhas completamente circundado por fibras \\
\hline 8 & Fibras extravasculares difusas pelo mesofilo \\
\hline 9 & Fibras extravasculares dispostas até a região correspondente ao bordo \\
\hline 10 & Número de fileiras de fibras extravasculares que ladeiam os feixes vasculares das folhas \\
\hline 11 & Bordo das folhas \\
\hline 12 & Tipo de estômato \\
\hline 13 & Corpos silicosos nos rizomas e pseudobulbos \\
\hline 14 & Ráfides \\
\hline 15 & Cutícula das folhas \\
\hline 16 & Cutícula dos pseudobulbos \\
\hline 17 & Cutícula dos rizomas \\
\hline 18 & Cristais irregulares nos pseudobulbos \\
\hline 19 & Formato das células epidérmicas dos pseudobulbos \\
\hline 20 & Formato das células epidérmicas dos rizomas \\
\hline 21 & Cristais poliédricos nos rizomas \\
\hline 22 & Número de camadas do córtex dos rizomas \\
\hline 23 & Número de camadas do velame \\
\hline 24 & Tipo de espessamento das células da exoderme \\
\hline 25 & Número de camadas do córtex das raízes \\
\hline 26 & Número de pólos de protoxilema \\
\hline 27 & Número de células de passagem \\
\hline 28 & Medula composta por células esclerificadas \\
\hline 29 & Medula composta por células parenquimáticas centrais e esclerificadas periféricas \\
\hline 30 & Estegmatas \\
\hline
\end{tabular}

espessas, indicando que alguns caracteres anatômicos refletem as condições abióticas do ambiente impostas ao seu modo de vida.

Este estudo contribui, sobremaneira, como o conhecimento morfo-anatômico do gênero Encyclia e, consequentemente, da subtribo Laeliinae, cuja anatomia tem se mostrado útil no subsídio de estudos filogenéticos, ecológicos, fisiológicos, e na delimitação e caracterização de complexos específicos, espécies crípticas e fenotipicamente polimórficas, assim como distintas categorias taxonômicas (ex., subfamílias, tribos, subtribos, gêneros, seções, espécies, dentre outras) (Baker 1972, Bonates 1993, Pires et al. 2003, Bonates 2007, Moreira et al. 2008, 2009, Stern \& Carlsward 2009, Noguera-Savelli \& Jáuregui 2011, Saoncella et al. 2017), revelando a necessidade e a promissoriedade de estudos micromorfológicos futuros direcionados ao gênero Encyclia, cuja anatomia ainda é escassamente conhecida. 
Quadro 2. Caracteres foliares, caulinares e radiculares distintivos entre as espécies estudadas. Presente (+); Ausente (-).

\begin{tabular}{|c|c|c|c|}
\hline CARACTERES & E. chapadensis & E. linearifolioides & E. osmantha \\
\hline 1 & - & + & + \\
\hline 2 & + & - & - \\
\hline 3 & $\begin{array}{c}\text { Arredondado com pequena } \\
\text { protuberância }\end{array}$ & Plano & Levemente anguloso \\
\hline 4 & $23-25$ & $20-22$ & $19-20$ \\
\hline 5 & Subepidérmica & Mediana & Subepidérmica \\
\hline 6 & + & + & - \\
\hline 7 & - & - & + \\
\hline 8 & + & + & - \\
\hline 9 & + & - & - \\
\hline 10 & 2 & 2 & 0 \\
\hline 11 & $\begin{array}{l}\text { Irregularmente obtuso, } \\
\text { Face adaxial de aspecto convexo e } \\
\text { abaxial côncavo }\end{array}$ & $\begin{array}{c}\text { Arredondado } \\
\text { Face adaxial de aspecto convexo e } \\
\text { abaxial côncavo }\end{array}$ & $\begin{array}{c}\text { Agudo, levemente fletido } \\
\text { Face adaxial de aspecto convexo e } \\
\text { abaxial plano }\end{array}$ \\
\hline 12 & Tetracítico & Tetracítico & Tetracítico/anomocítico \\
\hline 13 & - & + & + \\
\hline 14 & + & + & + \\
\hline 15 & Espessa & Delgada & Delgada \\
\hline 16 & Espessa & Delgada & Espessura média \\
\hline 17 & Ondulada & Irregular & Lisa \\
\hline 18 & - & + & - \\
\hline 19 & Ovoides & Arredondadas, elípticas ou oblongas & Arredondadas, elípticas ou oblongas \\
\hline 20 & Arredondadas ou ovoides & $\begin{array}{l}\text { Tabulares ou transversalmente } \\
\text { oblongas e elípticas }\end{array}$ & Arredondadas ou ovoides \\
\hline 21 & + & - & - \\
\hline 22 & $20-26$ & $20-35$ & $22-25$ \\
\hline 23 & $8-9$ & $7-8$ & $10-13$ \\
\hline 24 & $\mathrm{O}$ & $\mathrm{U}$ & $\mathrm{O}$ \\
\hline 25 & $8-9$ & $7-8$ & $10-14$ \\
\hline 26 & 9 & 10 & $18-19$ \\
\hline 27 & $2-3$ & $1-2$ & $1-2$ \\
\hline 28 & + & + & - \\
\hline 29 & - & - & + \\
\hline 30 & - & - & - \\
\hline
\end{tabular}

\section{AGRADECIMENTOS}

À Universidade Federal de Goiás (UFG), pela disponibilidade de transportes e instalações; ao Instituto Chico Mendes de Biodiversidade (ICMBio), pela permissão de coletas no Parque Nacional da Chapada dos Veadeiros; ao CNPq pelo apoio financeiro (Proc. $\mathrm{n}^{\circ}$.
445669/2014-4) ao projeto "Levantamento Florístico do Parque Nacional da Chapada dos Veadeiros, Goiás, Brasil" e pela concessão da bolsa de Iniciação Científica ao primeiro autor e a de Produtividade em Pesquisa ao terceiro (CNPq, processo $\mathrm{n}^{\circ}$. 307747/2019-0), e aos revisores que melhoraram significativamente o manuscrito. 


\section{REFERÊNCIAS}

Andreota, R.C., Barros, F. \& Sajo, M.G. 2015. Root and leaf anatomy of some terrestrial representatives of the Cranichideae tribe (Orchidaceae). Brazilian Journal of Botany 38(2):367-378.

Baker, R.K. 1972. Foliar anatomy of the Laeliinae (Orchidaceae). Ph.D. dissertation, Washington University, St. Louis, Missouri, USA

Barbosa-Rodrigues, J. 1882. Genera et species orchidearum novarum quas collegit, descripsit et iconibus illustravit 2: Adeneleuterophora - Rodriguezia. In: Genera et species orchidearum novarum 2. Typographia Nacional, Rio de Janeiro, p. 305.

Barbosa-Rodrigues, J. 1891. Genera et species orchidearum novarum. Vellosia 1:115-133.

Bastos, C.A., Meneguzzo, T.E.C. \& van den Berg, C. 2015. Taxonomic notes on Brazilian Encyclia (Orchidaceae: Laeliinae). Phytotaxa 218:77-83.

Benzing, D.H. \& Ott, D.W. 1981. Vegetative Reduction in Epiphytic Bromeliaceae and Orchidaceae: Its Origin and Significance. Biotropica 13(2):131-140.

Benzing, D.H., Ott, D.W. \& Friedman, W.E. 1982. Roots of Sobralia macrantha (Orchidaceae): structure and function of the velamenexodermis complex. American Journal of Botany 69:608-614.

Benzing, D.H. \& Pridgeon, A.M. 1983. Foliar trichomes of Pleurothallidinae (Orchidaceae): functional significance. American Journal of Botany 70(2):173-180.

Benzing, D.H., Friedman, W.E., Peterson, G. \& Renfrow, A. 1983. Shootlessness, velamentous roots, and the pre-eminence of Orchidaceae in the epiphytic biotope. American Journal of Botany 70:121-133

Blanco, G.D. 2017. Estudo Etnobotânico e Morfoanatômico de espécies de Orchidaceae utilizadas por grupos Guaraní. Dissertação 155 f., Universidade Federal de Santa Catarina, Santa Catarina.

Bonates, L.C.M. 1993. Estudos ecofisiológicos de Orchidaceae da Amazônia. II-Anatomia ecológica foliar de espécies com metabolismo CAM de uma campina da Amazônia central. Acta Amazonica 23:315-348.

Bonates, L.C.M. 2007. Anatomia ecológica da folha e da raiz e aspectos ecofisiológicos de Orchidaceae epífitas de uma campina da Amazônia Central. Tese 498 f., Universidade Federal do Amazonas, Amazonas.

Bray, C.M. \& West, C.E. 2005. DNA repair mechanisms in plants: crucial sensors and effectors for the maintenance of genome integrity. New Phytologist 168:511-528.

Brighigma, L., Fiordi, A.C. \& Palandri, M.R. 1984. Structural characteristics of mesophyll in some Tillandsia species. Phytomorphology 34:191-200.

Bukatsch, F. 1972. Bermerkungen zur Doppelfrbung Astrablau-Safranin. Mikrokosmos 61:255.

Cameron, D.D., Johnson, I., Leake, J.R. \& Read, D.J. 2007. Mycorrhizal acquisition of inorganic phosphorus by the green-leaved terrestrial orchid Goodyera repens. Annals of Botany 99:831-834.

Carlsward, B.S., Stern, W.L. \& Bytebier, B. 2006. Comparative vegetative anatomy and systematics of the Angraecoids (Vandae, Orchidaceae) with an emphasis on the leafless habit. Botanical Journal of Linnean Society 151:165-218.

Carlsward, B.S. \& Stern, W.L. 2009a. Comparative vegetative anatomy and systematics of Laeliinae (Orchidaceae). Botanical Journal of the Linnean Society 160:21-41.

Carlsward, B.S. \& Stern, W.L. 2009b. Vegetative anatomy and systematics of Triphorinae (Orchidaceae). Botanical Journal of the Linnean Society 159:203-210.

Chamberlain, C.J. 1932. Methods in plant histology. 5 ed. University of Chicago Press, Chicago. $416 \mathrm{p}$

Chomicki, G., Bidel, L.P.R., Ming, F., Coiro, M., Zhang, X., Wang, Y., Baissac, Y., Jay-Allemand, C., \& Renner, S.S. 2014a. The velamen protects photosynthetic orchid roots against UV-B damage, and a large dated phylogeny implies multiple gains and losses of this function during the Cenozoic. New Phytologist 205:1330-1341.

Chomicki, G., Bidel, L.P.R. \& Jay-Allemand, C. 2014b. Exodermis structure controls fungal invasion in the leafless epiphytic orchid Dendrophylax lindenii Lindl. Benth. ex Rolfe. Flora 209:88-94.
Christodoulakis, N.S. \& Psaras, G.K. 1987. Stomata on the primary root of Ceratonia siliqua. Annals of Botany 60:295-297.

Cogniaux, A.C. 1898. Orchidaceae: Epidendrum. In: Flora brasiliensis 3(5). Typographia Regia (Martius, C.F.P., Eicher, A.G. \& Urban, I. eds.), Munich, p. 29-185.

Costa, C.G. 1989. Morfologia e anatomia dos órgãos vegetativos em desenvolvimento de Marcgravia polyantha Delp. (Marcgraviaceae). Tese 227 f., Universidade de São Paulo, São Paulo.

Costa, N.M., Silva, N.A., Carvalho, R., Saoncella, A.L., Souza-Leal, T. \& Pedroso-de-Moraes, C. 2012. Anatomia radicial de Oncidium flexuosum Sims. e Oncidium Sharry Baby (Orchidaceae). Natureza on line 10(4):179-182.

Dangat, B.T. \& Gurav, R.V. 2016. Stomatal studies in the genus Habenaria (Orchidaceae). Richardiana 232-240.

Dearnaley, J.D.W. 2007. Further advances in orchid mycorrhizal research. Mycorrhiza 17:75-486.

Dettke, G.A., Sanches-Marques, A.M. \& Milaneze-Gutierre, A. 2007. Anatomia vegetativa de três espécies de Maxillaria Ruiz et Pavón (Orchidaceae). Revista Brasileira de Biociências 5(1):531-533.

Dressler, R.L. 1993. Phylogeny and classification of the orchid family. Dioscorides Press, Portland. 330 p.

Dycus, A.M. \& Knudson, L. 1957. The role of the velamen of the aerial roots of orchids. Botanical Gazette 119:78-87.

Eames, A.J. \& MacDaniels, L.H. 1925. An introduction to plant anatomy. New York: McGraw-Hill Book Company. 364 p.

Einzmann, H.J.R., Schickenberg, N. \& Zotz, G. 2019. Variation in root morphology of epiphytic orchids along small-scale and large-scale moisture gradients. Acta Botanica Brasilica 1-8.

Engard, C.J. 1944. Morphological identity of the velamen and exodermis in orchids. Botanical Gazette 105(4):457-462.

Esau, K. 1974. Anatomia das plantas com sementes. São Paulo: Edgard Blücher Ltda., São Paulo. 293 p.

Fernández-García, N., López-Berenguer, C. \& Olmos, E. 2014. Role of phi cells under abiotic stress in plants. In: Root engineering (Morte, A. \& Varma, A. eds.), Heidelberg: Springer, p. 23-37.

Figueroa, C., Salazar, G.A., Zavaleta, H.A. \& Engleman, E.M. 2008. Root character evolution and systematics in Cranichidinae, Prescottiinae and Spiranthinae (Orchidaceae, Cranichideae). Annals of Botany 101:509-520.

Haberlandt, G.F.J. 1914. Physiological plant anatomy. Macmillan Co. London.

Haas, D.L., Carothers, Z.B. \& Robbins, R.R. 1976. Observations on the phithickenings and casparian strips in Pelargonium roots. American Journal of Botany 63:863-867.

Holttum, R. 1955. Growth habitats of monocotyledons: variations on a theme. Phytomorphology 5:399-413.

Holtzmeier, M.A.N.N., Stern, W.L. \& Judd, W.S. 1998. Comparative anatomy and systematics of Senghas's cushion species of Maxillaria (Orchidaceae). Botanical Journal of Linnean Society 127:43-82.

Idris, N.A. \& Collings, D.A. 2015. The life of phi: the development of phi thickenings in roots of the orchids of the genus Miltoniopsis. Planta 241:489-506

Jansen, M.A., Gaba, V. \& Greenberg, B.M. 1998. Higher plants and UV-B radiation: balancing damage, repair and acclimation. Trends in Plant Science 3:131-135.

Joca, T.A.C., Oliveira, D.C., Zotz, G., Winkler, U. \& Moreira, A.S.F.P 2017. The velamen of epiphytic orchids: Variation in structure and correlations with nutrient absorption. Flora 230:66-74.

Joca, T.A.C., Oliveira, D.C., Zotz, G., Cardoso, J.C.F. \& Moreira, A.S.F.P. 2020. Chemical composition of cell walls in velamentous roots of epiphytic Orchidaceae. Protoplasma 257:103-118.

Johansen, D.A. 1940. Plant microtechnique. McGraw-Hill Book Co., New York.

Kedrovski, H.R. 2014. Anatomia radicular de espécies da subtribo Pleurothallidinae (Orchidaceae). Dissertação 113 f., Universidade Federal de Santa Catarina, Santa Catarina.

Krahl, A.H., Holanda, S.S., Krahl, D.R.P., Correa, M.M., Oliveira, R.L.C. \& Valsko, J.J. 2013. Anatomia foliar de Ananas lucidus Mill. (Bromeliaceae). Natureza on line 11(4):161-165. 
Krahl, A.H. \& Krahl, D.R.P. 2017. Anatomia foliar de Orleanesia yauaperyensis Barb. Rodr. (Orchidaceae). Biota Amazônia 7(4):63-65.

Kraus, B.H. 1949. Anatomy of vegetative organs of the pineapple Ananas comosus (L.) Merr. II. The leaf. Botanical Gazette 110(3):303-404.

Kraus, J.E. \& Arduin, M. 1997. Manual básico de métodos em morfologia vegetal. EDUR (Editora Universidade Rural), Rio de Janeiro. 198 p.

Kurzweil, H., Linder, H.P., Stern, W.L. \& Pridgeon, A.M. 1995. Comparative vegetative anatomy and classification of Diseae (Orchidaceae). Botanical Journal of the Linnean Society 117:171-220.

Leite, V.M.C. \& Oliveira, P.L. 1987. Morfo-anatomia foliar de Cattleya intermedia (Orchidaceae). Napea 2:1-10.

Madison, M. 1977. Vascular epiphytes: their systematic occurrence and salient features. Selbyana 2 (1):1-13.

Mackenzie, K.A.D. 1979. The development of the endodermis and phi layer of apple roots. Protoplasma 100:21-32.

Melville, L.H., Massicote, H.B. \& Peterson, R.L. 1987. Ontogeny of early stages of ectomycorrhizae synthesized between Dryas integrifolia and Hebeloma cylindrosporum. Botanical Gazette 148:332-341.

Meneguzzo, T.E.C., Bianchetti, L.B. \& Proença, C.E.B. 2012. O gênero Encyclia (Orchidaceae) no Distrito Federal, Goiás e Tocantins. Rodriguésia 63:277-292.

Mohana Rao, P.R. \& Khasim, S.M. 1987. Anatomy of three species of Bulbophyllum (Orchidaceae) with comments on their ecological adaptability and taxonomy. Proceedings Indian Academy Sciences (Plant Science) 97:391-397.

Moreira, A.S.F.P. \& Isaias, R.M.S. 2008. Comparative anatomy of the absorption roots of terrestrial and epiphytic orchids. Brazilian Archives of Biology and Technology 51:83-93.

Moreira, A.S.F.P., Fuhro, D. \& Isaias, R.M.S. 2008. Anatomia floral de Epidendrum fulgens Brongn. (Orchidaceae-Epidendroideae) com ênfase no nectário e sua funcionalidade. Revista de Biologia Neotropical 5(1):23-29.

Moreira, A.S.F.P., Filho, J.P.L., Zotz, G. \& Isaias, R.M.S. 2009. Anatomy and photosynthetic parameters of roots and leaves of two shadeadapted orchids, Dichaea cogniauxiana Shltr. and Epidendrum secundum Jacq. Flora 204:604-611.

Möbius, M. 1887. Über den anatomischen Bau der Orchideenblätter und dessen Bedeutung für das System dieser Familie. Jahrbücher für Wissenschaftliche Botanik 18:530-607.

Noguera-Savelli, E. \& Jáuregui, D. 2011. Anatomía foliar comparada y relaciones filogenéticas de 11 especies de Laeliinae con énfasis en Brassavola (Orchidaceae). Revista de Biología Tropical 59(3):1047-1059.

Oliveira, V.C. \& Sajo, M.G. 1999. Anatomia foliar de espécies epífitas de Orchidaceae. Revista Brasileira de Botânica 22:365-374.

Oliveira, V.C. \& Sajo, M.G. 2001. Morfo-anatomia caulinar de nove espécies de Orchidaceae. Acta Botanica Brasilica 15(2):177-188.

Oudemans, C. 1861. Ueber den Sitz der Oberhaut bei den Luftwurzeln der Orchideen. Verh Kon Ned Akad Wetensch 9:1-32.

Pan, C.X., Nakao, Y. \& Nii, N. 2006. Anatomical development of phi thickening and the Casparian strip in loquat roots. Journal of the Japanese Society for Horticultural Science 75:445-449.

Parrilla Díaz, A.T. \& Ackerman, J.D. 1990. Epiphyte roots: anatomical correlates to environmental parameters in Puerto Rican orchids. Orquídea 12(1):105-116.

Passioura, J.B. 1988. Water transport in and to roots. Annual Review of Plant Physiology and Plant Molecular Biology 39:245-265.

Pereira, O.L., Rollemberg, C.L. \& Kasuya, M.C.M. 2003. Association des mycorhizies dans les orchidees - perspectives d'utilisation dans les programmes de propagation symbiotique. Orchidees 55:24-27.

Pereira, O.L., Kasuya, M.C.M., Rollemberg, C.L. \& Chaer, G.M. 2005. Isolamento e identificação de fungos micorrízicos rizoctonióides associados a três espécies de orquídeas epífitas neotropicais no Brasil. Revista Brasileira de Ciências do Solo 29:191-197.

Peterson, C.A., Emanuel, M.E. \& Weerdenburg, C.A. 1981. The permeability of phi thickenings in apple (Pyrus malus) and geranium (Pelargonium hortorum) roots to an apoplastic fluorescent dye tracer. Canadian Journal of Botany 59:1107-1110.

Peterson, R.L., Uetake, Y. \& Zelmer, C. 1998. Fungal symbioses with orchid protocorms. Symbiosis 25:29-55.
Piazza, L.D., Smidt, E.C. \& Bona, C. 2015. Anatomia comparada dos órgãos vegetativos de espécies de Bulbophyllum seção Didactyle (Lindl.) Cogn. e Bulbophyllum seção Xiphizusa Rchb.f. (Orchidaceae). Hoehnea 42(1): 171-183.

Pires, M.F.O., Semir, J., Pinna, G.F.M. \& Felix, L.P. 2003. Taxonomic separation of the genera Prosthechea and Encyclia (Laeliinae: Orchidaceae) using leaf and root anatomical features. Botanical Journal of the Linnean Society 143:293-303.

Porembski, S. \& Barthlott, W. 1988. Velamen radicum micromorphology and classification of Orchidaceae. Nordic Journal of Botany $8: 117-137$

Pratikakis, E., Rhizopoulou, S. \& Psaras, G.K. 1998. A phi layer in roots of Ceratonia siliqua L. Botanica Acta 111:93-98.

Pridgeon, A.M., Stern, W.L. \& Benzing, D.H. 1983. Tilosomes in roots of Orchidaceae: morphology and systematic occurrence. American Journal of Botany 70(9):1365-1377.

Pridgeon, A.M. 1986. Anatomical adaptations in Orchidaceae. Lindleyana $1: 90-101$

Pridgeon, A.M. 1987. The velamen and exodermis of orchid roots. In: Orchid biology: reviews and perspectives IV (Arditti, J. ed.). Cornell University Press, Ithaca, p. 139-192.

Pupulin, F. \& Bogarín, D. 2012. A taxonomic revision of Encyclia (Orchidaceae: Laeliinae) in Costa Rica. Botanical Journal of the Linnean Society 168:395-448.

Ramírez, M., Niño, S. \& Berrío, T. 2016. Anatomía de la raíz de Encyclia cordigera (Kunth) Dressler (Orchidaceae). Revista Unellez de Ciencia y Tecnología 34:58-61.

Ribeiro, J.P.O., Paula-Souza, J. \& Silva, C.J. 2020. Morphoanatomy of vegetative organs of two species of Cattleya (Orchidaceae) native to Brazil. Rodriguésia 71:e01672017.

Rosa-Manzano, E., Andrade, J.L., Zotz, G. \& Reyes-García, C. 2014. Respuestas fisiológicas a la sequía, de cinco especies de orquídeas epífitas, en dos selvas secas de la Península de Yucatán. Botanical Sciences 92(4):607-616.

Rasmussen, H. 1987. Orchid stomata - structure, differentiation, function, and phylogeny. In: Orchid biology: reviews and perspectives, IV (Arditti, J. ed.). Cornell University Press, New York. 105-138 p.

Rosso, S.W. 1966. The vegetative anatomy of the Cypripedioideae (Orchidaceae). Botanical Journal of the Linnean Society 59:309-341.

Saoncella, A.L., Marteline, M.A. \& Pedroso-de-Moraes, C. 2017. Anatomia dos órgãos vegetativos de Cattleya violacea (Kunth) Rolfe (Orchidaceae). Iheringia, Série Botânica 72(1):114-126.

Sass, J.E. 1951. Botanical Microtechnique. $2^{\text {a }}$ ed. Ames, The Iowa State College Press, Iowa. 391 p.

Scatena, V.L. \& Nunes, A.C. 1996. Anatomia de Pleurothallis rupestris. Lindl. (Orchidaceae) dos campos rupestres. Boletim de Botânica da Universidade de São Paulo 15:35-43.

Silva, C.I. \& Milaneze-Gutierre, M.A. 2004. Caracterização morfoanatômica dos órgãos vegetativos de Cattleya walkeriana Gardner (Orchidaceae). Acta Scientiarum. Biological Sciences 26(1):91-100.

Silva, I.V., Meira, R.M.S.A., Azevedo, A.A. \& Euclydes, R.M.A. 2006. Estratégias anatômicas foliares de treze espécies de Orchidaceae ocorrentes em um campo de altitude no Parque Estadual da Serra do Brigadeiro (PESB) - MG, Brasil. Acta Botanica Brasilica 20(3):741-750.

Sinha, R.P. \& Häder, D.P. 2002. UV-induced DNA damage and repair: a review. Photochemical \& Photobiological Sciences 1:225-236.

Solereder, H. \& Meyer, F. 1930. Systematische Anatomie der Monokotyledonen. 6:92-242.

Staebner, A.N. 2012. The functional anatomy of aerial roots in orchids. Bachelorarbeit. 43 f., Universität Oldenburg, Alemanha.

Stern, W.L. \& Morris, M.W. 1992. Vegetative anatomy of Stanhopea (Orchidaceae) with special reference to pseudobulb water-storage cells. Lindleyana 7:34-53.

Stern, W.L., Cheadle, V.I. \& Thorsch, J. 1993a. Apostasiads, systematic anatomy, and the origins of Orchidaceae. Botanical Journal of the Linnean Society 111:411-455.

Stern, W.L., Aldrich, H.C., McDowell, L.M., Morris, M.W. \& Pridgeon, A.M. 1993b. Amyloplasts from cortical root cells of Spiranthoideae (Orchidaceae). Protoplasma 172:49-55. 
Stern, W.L., Morris, M.W., Judd, W.S., Pridgeon, A.M. \& Dressler, R.L. 1993c. Comparative vegetative anatomy and systematics of Spiranthoideae (Orchidaceae). Botanical Journal of the Linnean Society 113:161-197.

Stern, W.L. \& Judd, W.S. 2001. Comparative anatomy and systematics of Catasetinae (Orchidaceae). Botanical Journal of the Linnean Society $136: 153-178$.

Stern, W.L., Judd, W. \& Carlsward, B.S. 2004. Systematic and comparative anatomy of Maxillarieae (Orchidaceae), sans Oncidiinae. Botanical Journal of the Linnean Society 144:251-274.

Stern, W.L. \& Carlsward, B.S. 2006. Comparative vegetative anatomy and systematics of the Oncidiinae (Maxillarieae, Orchidaceae). Botanical Journal of the Linnean Society 152:91-107.

Stern, W.L. \& Carlsward, B.S. 2009. Comparative vegetative anatomy and systematics of Laeliinae (Orchidaceae). Botanical Journal of the Linnean Society 160:21-41.

Stern, W.L. 2014. Anatomy of the Monocotyledons: X. Orchidaceae. University Press, Oxford. 288 p.

Takane, R.J., Yanagisawa, S.S. \& Pivetta, K.F.L. 2010. Cultivo moderno de orquídeas: Cattleya e seus híbridos. Universidade Federal do Ceará, $179 \mathrm{p}$.

Thorsch, J. \& Stern, W.L. 1997. Tracheary studies and the terrestrial ancestry of Orchidaceae. International Journal of Plant Sciences 158(2):222-227.

van den Berg, C., Higgins, W.E., Dressler, R.L., Whitten, W.M., SotoArenas, M.A. \& Chase, M.W. 2009. A phylogenetic study of Laeliinae (Orchidaceae) based on combined nuclear and plastid DNA sequences. Annals of Botany 104:417-430.
Van Tieghem, P. 1888. Le réseau de soutien de l'ecorce de la racine. Annales des Sciences Naturelles, Botanique Series 7/8:375-378.

Van Tieghem, P. 1871. Recherches sur la symetrie de structure des plantes vasculaires. Annales des Sciences Naturelles, Botanique Series 13:3-315.

Vieira, A.C.M., Lainetti, R. \& Soares, A.P.C. 2000. Estudos farmacognósticos do Sumaré - Cyrtopodium paranaense Schltr. (Orchidaceae). Revista Brasileira de Farmacologia 81:11-13.

Weerdenburg, C.A. \& Peterson, C.A. 1983. Structural changes in phi thickenings during primary and secondary growth in roots. 1. Apple (Pyrus malus) Rosaceae. Canadian Journal of Botany 61:2570-2576.

Weltz, M. 1897. Zur Anatomie der monandrischen sympodialen Orchideen. $\mathrm{PhD}$ Thesis 65 f., University of Heidelberg, Alemanha.

Williams, C.A. 1979. The leaf flavonoids of the Orchidaceae. Phytochemistry 18:803-813.

Withner, C.L., Nelson, P.K. \& Wwjksnora, P.J. 1974. The anatomy of orchids. In: The orchids: scientific studies (Withner, C.L. ed.). John Wiley Co, New York, p. 267-334.

Yim, B., Smalla, K. \& Winkelmann, T. 2013. Evaluation of apple replant problems based on different soil disinfection treatments-links to soil microbial community structure? Plant and Soil 366:617-631.

Yukawa, T. \& Stern, W.L. 2002.Comparative vegetative anatomy and systematics of Cymbidium (Cymbidieae: Orchidaceae). Botanical Journal of the Linnean Society 138:383-419.

Zanenga-Godoy, R. \& Costa, C.G. 2003. Anatomia foliar de quatro espécies do gênero Cattleya Lindl. (Orchidaceae) do Planalto Central Brasileiro. Acta Botanica Brasilica 17(1):101-118. 